\title{
Ética en fotografía médica ¿Incumplimiento o desconocimiento?
}

\section{Ethics in medical photography,non-compliance or ignorance?}

\author{
Johana Acosta-Quiroz 1,a, Sebastian Iglesias-Osores 1,a
}

\section{Sr. Editor}

El uso de la fotografía como una herramienta en medicina se ha convertido en un componente importante de la evaluación de pacientes en muchas especialidades. Esta herramienta se utiliza cada vez más en la práctica contemporánea; ya que la fotografía puede mejorar planes de tratamiento. Además, la fotografía es un complemento en la educación y la investigación porque mejora la comunicación de los resultados ${ }^{(1)}$. Las imágenes digitales han brindado a los científicos nuevas oportunidades para adquirir y manipular datos utilizando técnicas que fueron difíciles o imposibles de emplear en el pasado. El objetivo de la carta es dar a conocer la problemática sobre la toma y uso de imágenes de pacientes, sin consentimiento e incumplimiento ético.

Los avances en tecnología digital, incluidos Internet y teléfonos inteligentes, han revolucionado la fotografía clínica. El uso de teléfonos inteligentes se está haciendo omnipresente entre los profesionales de la salud. Si bien la fotografía clínica tiene sus beneficios, con esta tecnología surgen nuevos problemas éticos, legales y sociales ${ }^{(2)}$. Esto se debe a múltiples factores, que incluyen avances significativos en la facilidad de captura de fotografías, junto con una evolución de los mecanismos de difusión de datos. La literatura para guiar a profesionales médicos, legales, gubernamentales y de negocios en temas relacionados con la fotografía médica es prácticamente inexistente ${ }^{(3)}$. Es una práctica común ilustrar libros de medicina con fotografías de pacientes. ¿En cuántos de estos casos los pacientes han dado un consentimiento válido para su publicación? El advenimiento de la imagen digital ha permitido almacenar, acceder y distribuir fotografías y grabaciones de video en todo el mundo con facilidad. En consecuencia, hay una creciente demanda de imágenes médicas. Una preocupación creciente en la comunidad científica es que las imágenes digitales no se manejan con suficiente cuidado. Las revistas y las sociedades profesionales han empezado a abordar el problema con pautas específicas de imágenes digitales.

¿El consentimiento válido para el uso de una fotografía en una publicación de libros cubre el uso de la misma fotografía en una publicación electrónica? En la mayoría de los casos, existe la duda de que haya suficiente documentación para averiguar para qué usos dieron consentimiento originalmente los pacientes ${ }^{(4)}$. La obtención de imágenes de pacientes sin un consentimiento totalmente informado no es ética y puede tener consecuencias graves. Todas las imágenes clínicas deben tomarse después de obtener el consentimiento total y deben mantenerse en un entorno regulado seguro para proteger la confidencialidad del paciente ${ }^{(5)}$.

Se debe de proteger la privacidad y autonomía del paciente ${ }^{(6)}$. Las fotografías son un recurso valioso, pero potencialmente dañino, por lo que se requiere un consentimiento informado, pero su forma puede variar según el contexto. Se debe de aplicar una jerarquía de difusión para evaluar qué tan detallado debe ser el consentimiento informado. Se debe tener cuidado de no causar daño, siendo los derechos especialmente de los niños la consideración más importante ${ }^{(7)}$. El consentimiento informado es esencial para el uso de la fotografía en medicina, pero no hay regulaciones o pautas establecidas para qué nivel de consentimiento recibir (8). Por lo tanto, la obtención de un consentimiento por escrito del paciente, un almacenamiento responsable

\footnotetext{
1. Facultad de Ciencias Biológicas, Universidad Nacional Pedro Ruiz Gallo, Lambayeque, Perú.

a. Biólogo Microbiólogo
} 
y seguro contribuye en gran medida a salvaguardar los intereses del paciente y del clínico. Las fotografías de cuerpo completo de pacientes intersexuales desnudos, por ejemplo, contravienen todos los deberes de la atención de los médicos, y no deben tomarse ni utilizarse para educación o publicación ${ }^{(5)}$ así como las fotografías médicas expuestas a sus pacientes generan al cirujano plástico a riesgos médico-legales. Debe conocer y cumplir con la ley para evitar posibles procedimientos legales ${ }^{(9)}$. La documentación del consentimiento expreso en el expediente clínico coloca al médico en una posición más defendible si se presenta una queja ante la junta médica o el comisionado de privacidad ${ }^{(15)}$.

Desafortunadamente, las pautas proporcionadas por las revistas o sociedades profesionales a menudo no vienen con instrucciones para explicar su importancia ${ }^{(10)}$. En un estudio se encontró que las imágenes clínicas en una revista ortopédica no cumplían con los estándares de calidad de imagen que se habían establecido previamente en los campos de la dermatología y la cirugía plástica. Subjetivamente, durante la revisión de estas imágenes, la opinión del autor fue que algunas imágenes, presentaban adecuadamente la información clínica, pero algunas podrían haber sido mejoradas por el cumplimiento de los estándares propuestos ${ }^{(11)}$.

Dada la frecuencia de uso y el grado de importancia que se otorga a la capacidad de enviar y recibir imágenes clínicas, el uso clínico de teléfonos inteligentes persistirá y probablemente aumentará con el tiempo. Una reciente decisión del General Medical Council Fitness to Practice ha puesto de relieve la necesidad de que los médicos e ilustradores médicos estén especialmente al tanto de no solo pedir consentimiento a los pacientes para las fotografías, sino también de que registren el consentimiento adecuadamente ${ }^{(13)}$. La cuestión del consentimiento (informado) a la fotografía médica ha sido desde hace mucho tiempo una cuestión desconcertante ${ }^{(14)}$. Los médicos deben obtener y documentar de forma rutinaria el consentimiento adecuado del paciente en relación con la fotografía clínica, utilizar configuraciones de privacidad estrictas en los teléfonos inteligentes y otros dispositivos digitales y garantizar que las imágenes se almacenen en estos dispositivos durante períodos mínimos.

Cualquiera que sea el estado del clínico, la toma de fotografías clínicas debe practicarse en el contexto de una ética profesional. Las mejores prácticas reconocen la necesidad de un consentimiento informado y las restricciones asociadas con la confidencialidad ${ }^{(16)}$. Es por esto que las medidas de privacidad y los protocolos estandarizados son imprescindibles. Se recomienda al personal de salud pedir el consentimiento de los pacientes antes de tomar una fotografía del paciente, el uso con fines de enseñanza no excluye esto, y se tiene que evitar compartir imágenes de pacientes por cualquier medio cuando no se tenga la autorización debida. Los centros de enseñanza superior así como los centros hospitalarios y colegios profesionales deben dar la pauta en la concientización de este tópico, reforzando la bioética en la enseñanza y dando lineamientos en su reglamento sobre cómo actuar ante esto. Se debe además, legislar para que el paciente tenga una protección no solo ética si no legal en el campo de la privacidad de datos.

Se concluye que debe existir transparencia del profesional de la salud frente al paciente al momento de tomar una fotografía biomédica (patología o condición clínica), así como, para el uso de la misma con fines de publicación; debiendo solicitarse el consentimiento antes de realizar la toma de las imágenes.

\section{REFERENCIAS BIBLIOGRÁFICAS}

1. Nguyen TT, VanderWalde L, Bellavance E, et al. Ethical Considerations of Medical Photography in the Management of Breast Disease. Ann Surg Oncol. 2018;25(10):2801-2806.

2. Van der Rijt R, Hoffman S. Ethical considerations of clinical photography in an area of emerging technology and smartphones. J Med Ethics. 2014;40(3):211-212.

3. Harting MT, DeWees JM, Vela KM, Khirallah RT. Medical photography: current technology, evolving issues and legal perspectives. Int $\mathrm{J}$ Clin Pract. 2015;69(4):401-409.

4. Hood CA, Hope T, Dove P. Videos, photographs, and patient consent. BMJ 1998;316(7136):1009-1011.

5. Creighton S, Alderson J, Brown S, Minto CL. Medical photography: ethics, consent and the intersex patient. BJU Int. 2002;89(1):62-67.

6. Bennett KG, Bonawitz SC, Vercler CJ. Guidelines for the ethical publication of facial photographs and review of the literature. Cleft Palate-Craniofacial J. 2019;56(1):7-14.

7. Devakumar D, Brotherton H, Halbert J, Clarke A, Prost A, Hall J. Taking ethical photos of children for medical and research purposes in low-resource settings: an exploratory qualitative study. 2013; 14(27):1-8.

8. Cho SI, Na J-I, Han S, Chung JH. Accepted Manuscript Comment on "Just a quick pic: Ethics of medical photography”: Generative adversarial networks could be a solution. J Am Acad Dermatol. 2019; 81(3): e85-e86.

9. de Runz A, Simon E, Brix M, et al. [Photography in plastic surgery: practices, uses and legislation]. Ann Chir Plast Esthet. 2015;60(1):12-18.

10. Cromey DW. Avoiding twisted pixels: ethical guidelines for the appropriate use and manipulation of scientific digital images. Sci Eng Ethics. 2010;16(4):639-67.

11. Uzun M, Bülbül M, Toker S, Beksaç B, Kara A. Medical photography: principles for orthopedics. Uzun al J Orthop Surg Res. 2014;9(23):1-7.

12. Abbott LM, Magnusson RS, Gibbs E, Smith SD. Smartphone use in dermatology for clinical photography and consultation: Current practice and the law. Australas J Dermatol. 2018;59(2):101-7.

13. Hill K. Consent, confidentiality and record keeping for the recording and usage of medical images. J Vis Commun Med. 2006;29(2):76-9.

14. Johns MK. Informed consent for clinical photography. J Audiov Media Med. 2002;25(2):59-63.

15. Kunde L, McMeniman E, Parker M. Clinical photography in dermatology: ethical and medico-legal considerations in the age of digital and smartphone technology. Australas J Dermatol. 2013;54(3):192-7.

16. Berle I. Clinical photography and patient rights: the need for orthopraxy. $J$ Med Ethics. 2008;34(2):89-92.

Revisión de pares: Recibido: 19/09/2019 Aceptado: 14/10/2019 